\title{
Association Between a Measure of Community Economic Distress and Medicare Patients' Health Care Utilization, Quality, Outcomes, and Costs
}

\author{
William B. Weeks, MD, PhD, MBA ', Mariétou H. L. Ouayogodé, PhD' , and James N. Weinstein, DO, \\ $M S^{1,2,3,4}$
}

${ }^{1}$ The Dartmouth Institute for Health Policy and Clinical Practice, Williamson Translational Building, DHMC, Lebanon, NH, USA; ${ }^{2}$ Dartmouth-Hitchcock Health, Lebanon, NH, USA; ${ }^{3}$ Amos Tuck School of Business, Hanover, NH, USA; ${ }^{4}$ Kellogg Business School, Northwestern University, Evanston, IL, USA.

KEY WORDS: health services research; health economics; Medicare.

J Gen Intern Med 33(9):1433-5

DOI: $10.1007 / \mathrm{s} 11606-018-4478-7$

() Society of General Internal Medicine 2018

\section{INTRODUCTION}

While geographic variation in Medicare health services utilization and costs has been studied for decades, recent work has suggested that community-level social determinants of health ${ }^{1}$ —including local economic activity ${ }^{2,3}$ — might explain geographically defined disparities in health service utilization and outcomes.

In the context of the aftermath of the Great Recession and its impact on healthcare needs, ${ }^{4}$ we sought to explore the relationship between community-level economic distress and Medicare patients' health care use, quality, outcomes, and costs.

\section{METHODS}

From the Dartmouth Atlas Project website (www. dartmouthatlas.org), we obtained publicly available mean 2011-2014 annual Medicare Part A and B age/sex/race/priceadjusted expenditures on fee-for-service (FFS) Medicare beneficiaries for inpatient, physician, outpatient, home health, and hospice care, and durable medical equipment (DME), at the hospital referral region (HRR) level. From that website's "Health care for an aging population," we obtained 2012 HRR-level data on Medicare FFS patients' demographics and health care utilization, quality (defined as receiving an annual wellness check, being prescribed high-risk medications, and, if diabetic, having all recommended tests completed), and outcomes (defined as rates of ambulatory care sensitive condition (ACSC) admissions, 30-day readmissions, and age/sex/raceadjusted morality). We present only 2012 expenditure data, though we found similar findings regardless of year used.

From the Economic Innovation Group (EIG) (www.eig.org/ dci), we obtained ZIP code-level 2017 Distressed Communities Index (DCI) scores. These scores evaluated relative

Published online May 9, 2018 economic distress by aggregating seven measures of local economic activity in 2011-2015: median ZIP code income as a percentage of the state's; local change in number of jobs and number of establishments; and the proportions of adults without a high school diploma or equivalent, adults not working, population living in poverty, and habitable housing currently unoccupied. EIG calculates DCI scores by ranking ZIP codes on each of those metrics, averaging them, and normalizing data to generate a relative measure of economic distress, ranging from 0 to 100 .

From ZIP code-level DCI scores, we calculated population-weighted HRR-level DCI scores and assigned 306 HRRs to quintiles, ranging from the least to the most economically distressed HRRs, based on those scores.

We used Pearson correlation statistics and analysis of variance to determine associations between community-level economic distress and measures of Medicare patients' demographics and health care use, quality, outcomes, and costs across distress quintiles.

\section{RESULTS}

Communities with the highest economic distress levels were more likely to be composed of Medicare beneficiaries who were black and concurrently enrolled in Medicaid (Table 1). Medicare FFS beneficiaries living in those communities used their local healthcare systems similarly to those living in communities with lower economic distress levels, although they were somewhat more likely to use primary care providers. Nonetheless, beneficiaries living in higher economic distress communities were less likely to have annual wellness checks, more likely to be prescribed high-risk medications, and less frequently received all recommended annual tests, if diabetic; further, they were more likely to be admitted for an ACSC, to be readmitted within 30 days of discharge, and to die.

Total Medicare expenditures were statistically significantly higher in communities with higher economic distress scores, as were expenditures on inpatient, home health, and hospice care, and DME (Table 2). 
Table 1 Relationship Between Distressed Community Index Score Quintile and Measures of 2012 Fee-for-Service Medicare Enrollees' Demographics, Health Care Utilization, Health Care Quality, and Health Care Outcomes at the Hospital Referral Region (HRR) Level $(N=306$ HRRs). All Measures of Use, Quality, and Outcomes Are Age, Sex, and Gender Adjusted. ACSC Means Ambulatory Care Sensitive Condition and ANOVA Means Analysis of Variance

\begin{tabular}{|c|c|c|c|c|c|c|c|c|}
\hline & \multicolumn{5}{|c|}{ Distressed Community Index score quintile } & \multirow{3}{*}{$\begin{array}{l}\text { ANOVA } \\
p \text { value }\end{array}$} & \multirow{3}{*}{$\begin{array}{l}\text { Pearson's } \\
r\end{array}$} & \multirow{3}{*}{$\begin{array}{l}\text { Pearson's } \\
p \text { value }\end{array}$} \\
\hline & Least & 2 & 3 & 4 & Most & & & \\
\hline $\begin{array}{l}\text { Mean Distressed Community Index score } \\
\text { (standard deviation) }\end{array}$ & $\begin{array}{l}28.4 \\
(5.5)\end{array}$ & $\begin{array}{l}40.3 \\
(2.5)\end{array}$ & $\begin{array}{l}48.8 \\
(2.5)\end{array}$ & $\begin{array}{l}58.3 \\
(3.0)\end{array}$ & $\begin{array}{l}69.7 \\
(5.0)\end{array}$ & & & \\
\hline \multicolumn{9}{|l|}{$\begin{array}{l}\text { Measures of } 2012 \text { fee-for-service Medicare enrollees'... } \\
\text { Demographics }\end{array}$} \\
\hline $\begin{array}{l}\text { Older than } 75(\%) \\
\text { Black race }(\%) \\
\text { Enrolled in Medicaid }(\%)\end{array}$ & $\begin{array}{l}6.10 \\
3.72 \\
8.24\end{array}$ & $\begin{array}{l}6.49 \\
4.63 \\
8.16\end{array}$ & $\begin{array}{l}6.73 \\
7.25 \\
8.67\end{array}$ & $\begin{array}{l}6.79 \\
7.94 \\
9.14\end{array}$ & $\begin{array}{l}6.35 \\
12.02 \\
12.11\end{array}$ & $\begin{array}{l}0.13 \\
<0.001 \\
<0.001\end{array}$ & $\begin{array}{l}0.08 \\
0.34 \\
0.30\end{array}$ & $\begin{array}{l}0.15 \\
<0.001 \\
<0.001\end{array}$ \\
\hline \multicolumn{9}{|l|}{ Health care utilization patterns } \\
\hline $\begin{array}{l}\text { Number of contact days with the healthcare } \\
\text { system }\end{array}$ & 16.0 & 16.3 & 16.7 & 16.4 & 16.1 & 0.58 & 0.002 & 0.97 \\
\hline $\begin{array}{l}\text { Mean number of clinicians providing care } \\
\text { Predominant provider is a primary care provider }(\%)\end{array}$ & $\begin{array}{l}3.26 \\
54.9\end{array}$ & $\begin{array}{l}3.30 \\
56.0\end{array}$ & $\begin{array}{l}3.33 \\
58.4\end{array}$ & $\begin{array}{l}3.24 \\
58.6\end{array}$ & $\begin{array}{l}3.17 \\
59.7\end{array}$ & $\begin{array}{l}0.14 \\
<0.001\end{array}$ & $\begin{array}{l}-0.09 \\
0.33\end{array}$ & $\begin{array}{l}0.10 \\
<0.001\end{array}$ \\
\hline \multicolumn{9}{|l|}{ Health care quality } \\
\hline Had an annual wellness check $(\%)$ & 12.03 & 11.59 & 9.84 & 8.98 & 8.23 & $<0.001$ & -0.31 & $<0.001$ \\
\hline Prescribed high-risk medications (\%) & 15.2 & 16.6 & 18.2 & 19.4 & 22.2 & $<0.001$ & 0.62 & $<0.001$ \\
\hline Diabetics with all recommended tests completed $(\%)$ & 55.6 & 54.9 & 53.4 & 51.5 & 49.5 & $<0.001$ & -0.36 & $<0.001$ \\
\hline \multicolumn{9}{|l|}{ Health care outcomes } \\
\hline Patients admitted with an ACSC (\%) & 3.54 & 3.96 & 4.20 & 4.60 & 4.96 & $<0.001$ & 0.54 & $<0.001$ \\
\hline 30 -day readmission rate $(\%)$ & 14.7 & 14.9 & 15.2 & 15.3 & 15.6 & $<0.001$ & 0.27 & $<0.001$ \\
\hline Mortality rate $(\%)$ & 4.09 & 4.38 & 4.55 & 4.75 & 5.03 & $<0.001$ & 0.68 & $<0.001$ \\
\hline
\end{tabular}

Table 2 Relationship Between Distressed Community Index Score Quintile and 2012 Fee-for-Service Medicare A and B Enrollees' Annual Per-Capita Part A and B Medicare Expenditures, in Total and Across Six Spending Categories at the Hospital Referral Region (HRR) Level $(N=306$ HRRs). Inpatient Includes Hospital and Skilled Nursing Facility (SNF) Expenditures; ANOVA Means Analysis of Variance

\begin{tabular}{|c|c|c|c|c|c|c|c|c|}
\hline \multirow{2}{*}{$\begin{array}{l}2012 \text { fee-for-service Medicare enrollees' annual per- } \\
\text { capita Part A and Part B expenditures, in total and } \\
\text { across six spending categories }\end{array}$} & \multicolumn{5}{|c|}{ Distressed Community Index score quintile } & \multirow{2}{*}{$\begin{array}{l}\text { ANOVA } \\
p \text { value }\end{array}$} & \multirow{2}{*}{$\begin{array}{l}\text { Pearson's } \\
r\end{array}$} & \multirow{2}{*}{$\begin{array}{l}\text { Pearson's } \\
p \text { value }\end{array}$} \\
\hline & Least & 2 & 3 & 4 & Most & & & \\
\hline Total & $\$ 8793$ & $\$ 9123$ & $\$ 9564$ & $\$ 9840$ & $\$ 10,088$ & $<0.001$ & 0.37 & $<0.001$ \\
\hline Inpatient (hospital and SNF) & $\$ 4009$ & $\$ 4212$ & $\$ 4390$ & $\$ 4595$ & $\$ 4698$ & $<0.001$ & 0.37 & $<0.001$ \\
\hline Physician & $\$ 2497$ & $\$ 2505$ & $\$ 2637$ & $\$ 2562$ & $\$ 2483$ & 0.50 & 0.004 & 0.94 \\
\hline Outpatient & $\$ 1335$ & $\$ 1372$ & $\$ 1343$ & $\$ 1434$ & $\$ 1396$ & 0.29 & 0.10 & 0.076 \\
\hline Home health & $\$ 396$ & $\$ 444$ & $\$ 539$ & $\$ 570$ & $\$ 748$ & $<0.001$ & 0.38 & $<0.001$ \\
\hline Hospice & $\$ 336$ & $\$ 357$ & $\$ 396$ & $\$ 421$ & $\$ 470$ & $<0.001$ & 0.30 & $<0.001$ \\
\hline Durable medical equipment & $\$ 224$ & $\$ 236$ & $\$ 251$ & $\$ 262$ & $\$ 285$ & $<0.001$ & 0.53 & $<0.001$ \\
\hline
\end{tabular}

\section{DISCUSSION}

We found that higher community levels of economic distress were associated with lower health care quality, worse health care outcomes, and higher health care costs.

These findings suggest a relationship between local economic distress and poor health care value among Medicare FFS beneficiaries at the community level. While our study is limited by its reliance on existing datasets, use of postrecession economic and health service utilization data, and focus on the FFS Medicare population, they support contentions that social determinants of health - and particularly economic prosperity - are associated with community-level health and health care.

While this cross-sectional work was not designed to evaluate the impact of changes in economic distress fostered by economic shocks like the Great Recession, evaluation of the impact of such shocks on economic distress, health, and healthcare consumption would inform development of programs that impart economic stability in the community to economic shocks - such as basic income levels ${ }^{5}$ - and have the potential to improve local health outcomes, reduce healthcare costs, and improve healthcare value, particularly for the most vulnerable populations.

Acknowledgements: The data used in this analysis was obtained from The Dartmouth Atlas, which is funded by the Robert Wood Johnson Foundation and the Dartmouth Clinical and Translational Science Institute, under award number UL1TR001086 from the National Center for Advancing Translational Sciences of the National Institutes of Health.

This paper used propriety data provided by the Economic Innovation Group. The findings expressed in this article are solely those of the authors and not necessarily those of the Economic Innovation Group. The Economic Innovation Group does not guarantee the reliability of, or necessarily agree with, the information provided herein.

Dartmouth College has determined that analysis of Dartmouth Atlas Data does not constitute human subjects research. 
Corresponding Author: William B. Weeks, MD, PhD, MBA; Dartmouth-Hitchcock Health, Lebanon, NH, USA (e-mail: wbw@dartmouth. edu).

\section{Compliance with Ethical Standards:}

Conflict of Interest: The authors declare that they do not have a conflict of interest.

\section{REFERENCES}

1. Communities in Action: Pathways to Health Equity. Washington, DC: National Academies of Sciences, Engineering, and Medicine; 2017.
2. Weeks WB, Weinstein JN. Per-capita Medicare expenditures, primary care access, mortality rates, and the least healthy cities in America. The American journal of medicine 2017;130:101-4.

3. Krumholz HM, Normand ST, Wang Y. Geographical health priority areas for older Americans. Health affairs (Project Hope) 2018;37:104-10.

4. Huang J, Birkenmaier J, Kim Y. Job loss and unmet health care needs in the economic recession: different associations by family income. American journal of public health 2014;104:e178-83.

5. Painter A. A universal basic income: the answer to poverty, insecurity, and health inequality? BMJ (Clinical research ed) 2016;355:i6473. 